\title{
Effect of additives on electroless silver plating
}

\author{
Xu Wang ${ }^{1}$, Cheng Zhang ${ }^{1, a}$, Hongqiang Zhou ${ }^{2, \text { b,* }}$ \\ ${ }^{1}$ College of Chemical Engineering, Zhejiang University of Technology \\ ${ }^{2}$ College of Ecology, Lishui University \\ ${ }^{a}$ Cheng Zhang: czhang@zjut.edu.cn; ${ }^{b}$ Hongqiang Zhou: qlzhq@13.com
}

Keywords: Electroless silver plating; additives; DL-Methionine.

\begin{abstract}
The effect of DL-Methionine (DM) on the electroless silver deposition was investigated. The deposition rate of electroless silver deposition was inhibited by an addition of DM. The effects of DM on the polarization curves were studied by LSV. Not only the anodic oxidation reaction but also cathodic reduction reaction was inhibited by DM addition. The crystallinity of electroless plated silver film was decreased by an addition of DM.
\end{abstract}

\section{Introduction}

Electroless plating is a variety of chemical deposition technology, involving the deposition of metals from solutions onto surfaces without applying an external electric voltage [1, 2]. Ag has been extensively used in jewellery, silverware, fuses and medical instruments as a lustrous metal with the highest thermal and electrical conductivities of all the metals. Conventional electroless Ag plating is normally carried out from cyanide baths with a common reducing agent such as formaldehyde.

Although many researches had been achieved by experimental approaches such as electrochemical and kinetic analyses[3-6], the mechanism of electroless silver plating was so complex that a reasonable model had not been established, many aspects of the electroless plating process have not been explored yet. Kim's group reported the effects of $\mathrm{CuCN}$ on silver electroplating process by linear sweep voltammetry and silver deposition rate [5]; An's group reported the effects of 2-Butyne-1,4-diol on silver electroplating process by cyclic voltammetry[6]. But the mechanism of additives for the deposition rate for electroless silver had not been reported.

In the article, the effects of additive on the deposition rate of the electroless silver bath and the polarization curves by (linear sweep voltammetry) LSV were studied, the effects of additive on the activation energy of the reaction Ea was investigated. The crystalline nature of electroless Ag on ABS plastic was also studied using XRD

\section{Experimental}

A general acrylonitrile-butadiene-styrene (ABS) resin laminate with a thickness of $1.5 \mathrm{~mm}$ and an area of $30 \times 20 \mathrm{~mm}$ was used in the present research. All the reagents used were of analytical reagent grade. Before the electroless silver plating, the surface of the ABS resin laminate was pretreated as done in the literature.[7] The surface activation process of the ABS resin laminate was carried out by an activation solution (CATAPOSIT44, purchased from Rohm and Haas Co.) at $45^{\circ} \mathrm{C}$ for 5 min, and then the laminate was immersed in $10 \%$ hydrochloric acid $(\mathrm{HCl})$ for $1 \mathrm{~min}$. Distilled water was used to wash the laminate after every step.

The composition of the electroless silver plating solution was $\mathrm{AgNO}_{3} 0.045 \mathrm{~mol} \mathrm{~L}^{-1}, \mathrm{NH}_{3} \cdot \mathrm{H}_{2} \mathrm{O}$ (Ammonium Hydroxide) $0.65 \mathrm{~mol} \mathrm{l}^{-1}$ and $\mathrm{C}_{4} \mathrm{O}_{6} \mathrm{H}_{4} \mathrm{KNa}$ (Seignette Salt) $0.05 \mathrm{~mol} \mathrm{~L}^{-1}$ as a reducing agent. $\mathrm{C}_{5} \mathrm{H}_{11} \mathrm{NO}_{2} \mathrm{~S}$ (DL-Methionine) was varied from 0 to $3.0 \mathrm{~g} / \mathrm{L}$ as stabilizing agent.

The rates of electroless silver deposition were determined by the change in weight of the ABS resin after 30 min plating, assuming uniform plating and bulk density.

For linear sweep voltammetry (LSV), an $\varphi 3.0 \mathrm{~mm}$ pure silver electrode was used as the working electrode, and $4.0 \mathrm{~cm}^{2}$ platinum sheet and a commercial electrode of $\mathrm{Hg} / \mathrm{Hg}_{2} \mathrm{Cl}_{2}$ saturated with $\mathrm{KCl}$ 
were used as the counter and reference electrodes, respectively. LSV experiments were carried out at $25^{\circ} \mathrm{C}$ and at a scan rate of $15 \mathrm{mV} \mathrm{s}^{-1}$. The anodic polarization curves were measured in the plating bath without Seignette Salt. The crystalline structures of electroless plated silver film were measured by an X-ray diffractometer (XRD, D/MAX-3C Rigaku Co., Ltd.) using $\theta$-2 $\theta$ scan with a Cu Ka source working at $45 \mathrm{kV}$ and $35 \mathrm{~mA}$.

\section{Results and discussion}

The effect of the addition of DM on the deposition rate of traditional electroless silver plating was measured, and the results are shown in Fig 1. In Fig. 1, the deposition rate of electroless silver plating decreased from 6.70 to $0.28 \mu \mathrm{m} \mathrm{h}^{-1}$ with a DM concentration from 0 to $2.5 \mathrm{~g} / \mathrm{L}$, which indicated that the addition of DM inhibited the silver deposition. Figure 2 showed the logarithm of silver deposition rate as a function of $T^{-1}$. In Fig. 2, a linear relationship between the logarithm of silver deposition rate and $T^{-1}$ was obtained. According to the Arrhenius equation

$$
\ln v=-E_{a} / R T+B
$$

Where $v$ is the reaction rate, $E a$ is the activation energy, $R$ is the universal gas constant, and $T$ is the thermodynamic temperature, the activation energy of the reaction Ea could be obtained. By calculation, the activation energy of the deposition reaction for electroless silver plating with the DM concentration of $1.5 \mathrm{~g} \mathrm{~L}^{-1}$ was $21.86 \mathrm{~kJ} \mathrm{~mol}^{-1}$; when the $\mathrm{DM}$ concentration was $2.5 \mathrm{~g} \mathrm{~L}^{-1}$, the activation energy decreased to $35.29 \mathrm{~kJ} \mathrm{~mol}^{-1}$, which indicated that the reaction activation energy of electroless silver deposition increased with an addition of DM. The result was in line with the inhibiting effect of DM during electroless silver plating.

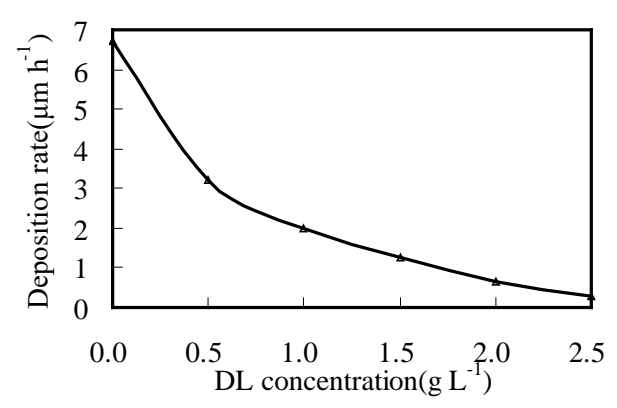

Fig.1 The effect of DM concentration on the deposition

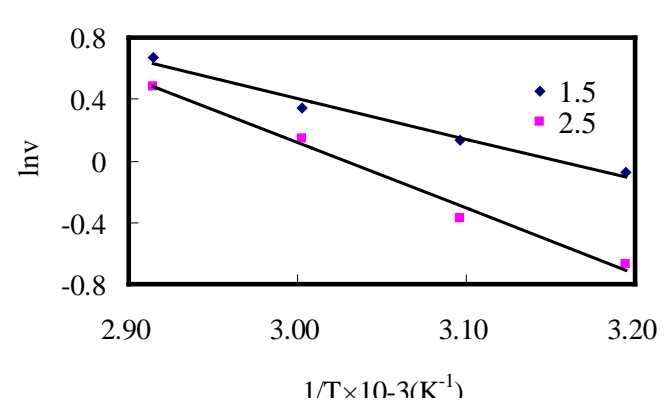

Fig. 2 Logarithm of electroless Ag deposition rate as function of $\mathrm{T}^{-1}$ in the concentration of $1.5 \mathrm{~g} \mathrm{~L}^{-1}$ and $25 \mathrm{o} \mathrm{I}^{-1} \mathrm{DM}$

To explore the inhibiting mechanism of DM for silver deposition, the linear sweep voltammetry measurements were used to investigate the effects of DM concentration on the polarization curves of the electroless silver solution (Fig.3).
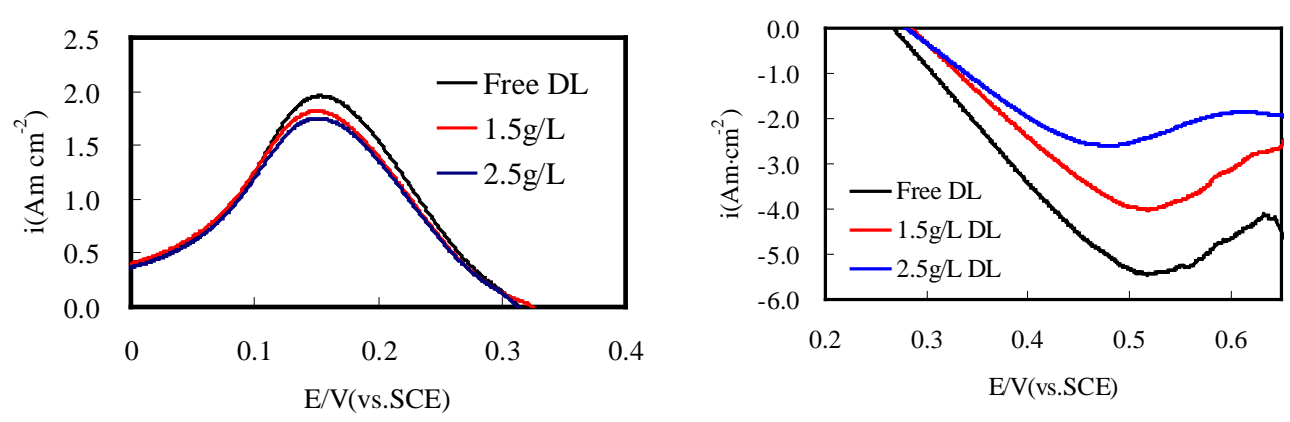

Fig. 3 Effect of DM on the polarization behavior of electrolyte for electroless silver plating (a) anodic polarization, (b) cathodic polarization. 
To gain further insight into the mechanism of DM, the effects of DM on the polarization curves were studied by LSV, and the results are shown in Fig. 5. The polarization behaviors of silver reduction and potassium sodium tartrate tetrahydrate oxidation depended on the addition of DM. For the cathodic reduction reaction (Fig. 3a), the reduction peak potential changed small with the addition of the additives but the reduction peak current changed markedly with the addition of the additives. The reduction peak current was $1.95 \mathrm{~mA} \mathrm{~cm}^{-2}$ with additive free, it decreased to $1.81 \mathrm{~mA} \mathrm{~cm}^{-2}$ with an addition of DM $\left(1.5 \mathrm{~g} \mathrm{~L}^{-1}\right)$ and decreased to $1.74 \mathrm{~mA} \mathrm{~cm}^{-2}$ with $2.5 \mathrm{~g} \mathrm{~L}^{-1}$.

For the anodic reaction (Fig. 3b), not only the oxidation peak potential but also the oxidation peak current of potassium sodium tartrate tetrahydrate changed with the addition of the additives. The oxidation peak potential changed small with the addition of the additives but the oxidation peak current changed markedly with the addition of the additives. The oxidation peak current was -5.43 $\mathrm{mA} \mathrm{cm}{ }^{-2}$ with additive free, it decreased to $-4.02 \mathrm{~mA} \mathrm{~cm}^{-2}$ with an addition of DM(1.5 $\left.\mathrm{g} \mathrm{L}^{-1}\right)$ and decreased to $-2.61 \mathrm{~mA} \mathrm{~cm}^{-2}$ with $2.5 \mathrm{~g} \mathrm{~L}^{-1}$.

Bath the positive shift of the oxidation peak potential and the decrease in the oxidation peak current and the reduction peak current are detrimental to the deposition of electroless silver. Not only the anodic oxidation reaction but also the cathodic reduction reaction were inhibited by an addition of DM, bath the anodic oxidation reaction and cathodic reduction reaction were suppressed completely by the addition of SPS and PEG. And so, the deposition rate was suppressed by an addition of DM. The changes in oxidation peak potential and the oxidation and reduction peak current of the plating bath with an addition of DM was in significant agreement with that of the deposition rates.

The shift of the reduction current of $\left[\mathrm{Ag}\left(\mathrm{NH}_{3}\right)_{2}\right]^{+}$may be explained as follows: Because of structure, the complex $\left[\mathrm{Ag}\left(\mathrm{NH}_{3}\right)_{2}\right]^{+}$was changed to a mixed ligand complex $\left[\mathrm{Ag}\left(\mathrm{NH}_{3}\right)(\mathrm{DM})\right]^{+}$with the addition of DM. Because the complex $\left[\mathrm{Ag}\left(\mathrm{NH}_{3}\right)_{2}\right]^{+}$was easier to be reduced than the complex $\left[\mathrm{Ag}\left(\mathrm{NH}_{3}\right)(\mathrm{DM})\right]^{+}$, the reduction current of the complex to metal silver with DM addition was shifted to the positive direction and the deposition rate of electroless silver was inhibited.

The crystallography of electroless plated Ag film deposited in the plating bath containing DM was characterized by X-ray diffraction. For the electroless plated Ag film deposited in additive free bath, the peak intensity ratio $\mathrm{I}(111) / \mathrm{I}(200)$ was 1.78 and the full width at half-maximum (fwhm) of (111) for $2.2 \mu \mathrm{m}$ thick Ag film was $0.331^{\circ}$ (see Fig. 4). When the DM concentration was $1.5 \mathrm{~g} \mathrm{~L}-1$, the peak intensity ratio $\mathrm{I}(111) / \mathrm{I}(200)$ was 1.92 and the fwhm of (111) for $2.2 \mu \mathrm{m}$ thick Ag film was $0.336^{\circ}$ (see Fig. 4); When the DM concentration was $2.5 \mathrm{~g} \mathrm{~L}-1$, the peak intensity ratio $\mathrm{I}(111) / \mathrm{I}(200)$ was 2.08 and the fwhm of (111) for $2.2 \mu \mathrm{m}$ thick Ag film was $0.337^{\circ}$. According to Scherrer's formula,[8,9] the results indicated that the crystallinity of electroless plated silver film was decreased by an addition of DM.

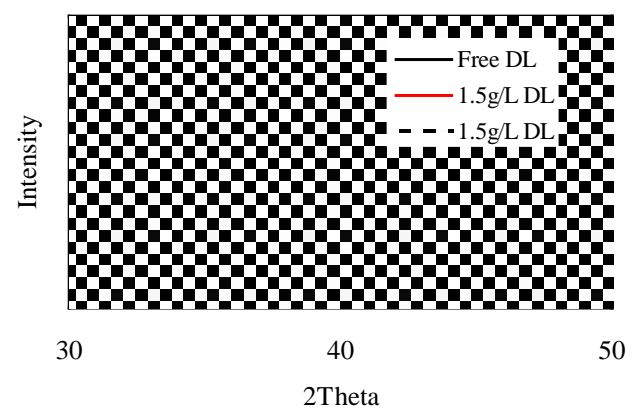

Fig. 4 XRD patterns of electroless plated Ag films.

\section{Conclusion}

The effect of DM on the electroless silver deposition was investigated. The deposition rate of electroless silver deposition was inhibited by an addition of DM. The effects of DM on the polarization curves were studied by LSV. Not only the anodic oxidation reaction but also cathodic 
reduction reaction was inhibited by DM addition. The crystallinity of electroless plated silver film was decreased by an addition of DM.

\section{Acknowledgments}

This work was supported by Provincial Natural Science Foundation of Zhejiang (Y14E010005)

\section{References}

[1] Y. Shacham-Diamand, V. Dubin, and M. Angyal, Thin Solid Films, 262, 1 (1995).

[2] J.B. Hajdu, Plating Surf. Finish. 83 (1996) 29.

[3] E. Groshart, Met. Finish. 70 (1972) 85.

[4] G.V. Elmore, R.F. Hershberger, J. Electrochem. Soc. 121(1974) 107.

[5] S. K. Cho, J. K. Lee, S. K. Kim, J. J. Kim, Electrochemical and Solid-State Letters, 10(10) D116-119, (2007)

[6] J. F. Liu, M. Z. An, H. Y. Zheng, Rare metals, 25,p255(2006)

[7]H. Jiang, Z. Liu, Xi. Wang, and Z. Wang, Trans. Inst. Met. Finish., 85, 103 (2007).

[8] E. Norkus and A. Vaskelis, Russ. J. Inorg. Chem., 32, 130 (1987).

[9] J. J. Kim, S. K. Kim, and Y. S. Kim, J. Electroanal. Chem., 61, 542 (2004). 